\title{
Effect of structural animal health planning on antimicrobial use and animal health variables in conventional dairy farming in the Netherlands
}

\author{
David C. Speksnijder, ${ }^{* 1}$ Haitske Graveland, ${ }^{*}$ Ineke A. J. M. Eijck,† René W. M. Schepers, $\ddagger$ \\ Dick J. J. Heederik, § Theo J. M. Verheij,\# and Jaap A. Wagenaar*I \\ *Department of Infectious Diseases and Immunology, Faculty of Veterinary Medicine, Utrecht University, PO Box 80165, 3508 TD Utrecht, \\ the Netherlands \\ †Eijck Interim Management, 8219 AM Lelystad, the Netherlands \\ $\ddagger$ Schepers Adviseurs, 7201 AV Zutphen, the Netherlands \\ §Institute for Risk Assessment Sciences, Faculty of Veterinary Medicine, Utrecht University, PO Box 80178, 3508 TD Utrecht, the Netherlands \\ \#Julius Center for Health Sciences and Primary Care, University Medical Center, Utrecht, PO Box 85500, 3508 GA Utrecht, the Netherlands \\ ॥Wageningen Bioveterinary Research, PO Box 65, 8200 AB Lelystad, the Netherlands
}

\begin{abstract}
Widespread veterinary use of antimicrobials might contribute to the increasing burden of antimicrobial resistance. Despite many successful efforts to reduce veterinary antimicrobial use in the Netherlands, antimicrobial use on a substantial number of farms has remained relatively high over the past few years. Farm-specific solutions are required to further lower antimicrobial use on these farms. Reducing the burden of animal diseases at the farm level by means of a structured approach to animal health planning could be promising. This intervention study aimed to evaluate the main effects of an animal health planning program developed by an advisory team consisting of a dairy farmer, his veterinarian, and his feed adviser under the guidance of a professional facilitator. During an initial farm visit, the advisory team developed a farm-specific animal health planning program with support from the facilitator. After $1 \mathrm{yr}$, the effects of this program on animal health, production parameters, and antimicrobial use were evaluated and compared with control farms that did not have a facilitated animal health planning program. Antimicrobial use on intervention farms was significantly reduced between the start and the end of the study period; however, no significant differences in the rate of reduction between the intervention and control groups could be observed $(-19 \%$ and $-14 \%$, respectively). Reduced antimicrobial use did not result in negative effects on animal health and production parameters during the study period in both groups. On intervention farms, a significant positive relationship was found between the percentage of completed action
\end{abstract}

Received August 26, 2016

Accepted February 4, 2017.

${ }^{1}$ Corresponding author: d.c.speksnijder@uu.nl points at farm level and the percentage reduction in antimicrobial use. The level of compliance with action points and the quality of collaboration between farmer and advisers were positively associated with the accomplishment of corresponding objectives. However, the total number of objectives was negatively associated with the level of compliance with action points and tended to be negatively associated with the percentage reduction in antimicrobial use at farm level. Gradually reducing antimicrobial use without adverse effects on animal health and productivity is possible by adjusting management practices in a team effort. Fostering good collaboration among farmer, veterinarian, and feed adviser and focusing on a limited number of objectives have positive effects on the outcomes of the animal health planning program and antimicrobial use.

Key words: facilitated animal health planning, antimicrobial use, implementation, continuous improvement

\section{INTRODUCTION}

In recent decades, it has become apparent that extensive antimicrobial use (AMU) in food-producing animals might contribute to the increasing burden of antimicrobial resistance (WHO, 2012; Van Boeckel et al., 2015). Recent evidence shows that reducing AMU in livestock is associated with reducing antimicrobial resistance levels in farm animals (Dorado-García et al., 2016). Lowering AMU in farm animals therefore can be an effective strategy for containing the increasing burden of antimicrobial resistance (Agers $\varnothing$ and Aarestrup, 2013). Several countries have introduced successful policy measures over recent decades to reduce AMU in farm animals (Grave et al., 2006; WHO, 2012; MARAN, 2015). In the Netherlands, measures include strict mandatory reduction targets set by the national 
government combined with private initiatives to accomplish this objective (Speksnijder et al., 2015c). However, there is great variation in AMU between farms in the Netherlands, indicating that there is room for further improvement on farms with higher than average AMU (Stichting Diergeneesmiddelen Autoriteit, 2014).

Many animal health problems are still highly prevalent in modern farming systems. Thus, focusing on the prevention of (infectious) diseases could be an effective approach in AMU reduction (Speksnijder et al., 2015a; Tremetsberger and Winckler, 2015; WHO, 2015). Major advances in understanding animal diseases allow us to substantially reduce or prevent animal diseases (LeBlanc et al., 2006). The challenge, however, is to correctly identify risk factors for animal health, develop and consistently implement the required management practices, and thoroughly evaluate these in a structured animal health planning process (LeBlanc et al., 2006; Vaarst et al., 2006; Green et al., 2007; Ivemeyer et al., 2012; Postma et al., 2015; Speksnijder et al., 2015a; Tremetsberger and Winckler, 2015). Crucial herein is that animal health planning is farm specific, warrants high involvement of the farmer during the development and implementation phases, and includes clear action points that are unambiguous for those involved (Kristensen and Jakobsen, 2011; Ivemeyer et al., 2012).

Veterinarians increasingly are seen as animal health advisers and potentially play an important role in both the animal health planning process and the reduction of AMU. The success of veterinarians in this role relies on their abilities to elicit farmers' opinions and values, communicate information clearly to farmers in a context of goal setting and regular evaluation, and encourage farmers in the implementation of agreed action points in a continuous cycle of improvement. This is challenging and often fails in practice (Clark et al., 2001; Jansen et al., 2010; Kristensen and Jakobsen, 2011; Derks et al., 2012; Main et al., 2012; Whay et al., 2012; Speksnijder et al., 2015a; Tremetsberger and Winckler, 2015).

Several recent studies have tried, with varying degrees of success, to improve animal health parameters through the development and implementation of farmspecific animal health plans, especially in dairy farming. Most of these studies focused on only one health problem (e.g., udder health, claw health), and most did not include control farms. To a great extent in these studies, external technical specialists (e.g., academic staff, disease specialists) performed risk assessments and formulated the animal health plans (Green et al., 2007; Bell et al., 2009; Ivemeyer et al., 2012; Whay et al., 2012; Tremetsberger et al., 2015; Tremetsberger and Winckler, 2015). Although the outcomes of these studies are useful for assessing the effectiveness of specific interventions on certain animal health indicators, ultimately the farm veterinarian, farmer, and other farm advisers should collaborate in a structured approach to animal health planning. Therefore, we conducted a pragmatic randomized controlled trial over a 1-yr period to test the main effects of an animal health planning program conducted by an advisory team consisting of a dairy farmer, his veterinarian, and his feed adviser under the guidance of a professional facilitator. Our aim was to evaluate this facilitated approach to animal health planning and its effects on animal health, production parameters, and AMU compared with control farms.

\section{MATERIALS AND METHODS}

More details of the study protocol are described in the Supplemental Material (https://doi.org/10.3168/ jds.2016-11924).

\section{Farm Selection}

The study named Samen Beter Boeren ("Better Farming Together") was conducted between March 2014 and June 2015 in the Netherlands. Dairy farmers, as well as their veterinarian and feed adviser, were voluntarily recruited through advertisements on popular farming websites and through extension officers of the biggest dairy company in the Netherlands. Farmers were eligible for participation if they had an average yearly AMU within the signaling zone at that time (between 3 and 6 defined daily dose animal, DDDA; Stichting Diergeneesmiddelen Autoriteit, 2014). Being in the signaling zone was a warning for farmers with a higher than average AMU but did not require immediate additional measures. This AMU criterion was chosen because there was room for improvement in AMU on these farms and because relatively few farms had moved to a lower benchmarking zone over the past few years. After randomization, 20 farms were assigned to the intervention group and 19 farms were assigned to the control group. An introductory meeting was held before the start of the study to explain the background of the study to all participants in both the intervention and control groups. The farms in the intervention group were enrolled in the intervention activities, whereas on the control farms only data were gathered during the study period. After the study ended, farms in the control group were enrolled in the intervention. During the study period, all participants received 2 newsletters describing general affairs related to the project (without details on the content of the intervention) and 
a summary of the introductory meeting. To minimize placebo effects, no other contact was made with control farms during the study period. By the end of the study period, 4 dairy farmers from the control group decided not to continue with the study due to personal problems or loss of interest, resulting in a final control group of 15. Ethical board review was not required for this study.

\section{Animal Health Planning Process}

Preparation. Prior to the start of the study, participating veterinarians followed a course on communication and advisory skills (Figure 1). Farmers and feed advisers were invited to follow an e-learning course on structural animal health planning. Each member of the advisory team (farmer, veterinarian, and feed adviser) submitted an intake form describing the participant's view on the current performance and points for improvements related to animal health.

Intake Farm Visits. Participating farms were randomly assigned to 1 of the 2 professional facilitators (IE and RS) who facilitated the animal health planning process during the study period. The explicit task of the facilitator was to create a culture of teamwork with fruitful discussion and to ensure that objectives and action points were supported by all participants. The facilitator's role was not to share technical knowledge and advice. The facilitators used the intake forms to prepare for the initial farm visit. After a short farm walk, the advisory team started the development of their own animal health plan. Specific, measurable, acceptable, realistic, and timely (SMART) objectives were set, priorities were chosen, and action points were planned.

The action points were summarized on a laminated activity plan (A2 paper size: $420 \times 594 \mathrm{~mm}$ ), which was returned to the farmer as a reminder. The facilitators also provided feedback for individual participants to improve their collaboration on animal health planning in the future.

After approximately 4 and 8 mo, facilitators approached the participants by telephone and e-mail to remind them about the activity plan, monitor progress in the implementation of the action points according to the timetable in the action plan, and support advisory teams that encountered difficulties in the implementation. After $1 \mathrm{yr}$, a final farm visit with the facilitator was planned in which the collaboration as a team, the implementation of the activity plan, and the objectives were evaluated. After this evaluation process, the advisory team was challenged to develop a new animal health plan for the upcoming year.

\section{Data Collection}

The facilitator assessed the quality of the animal health planning process per farm by assigning a score

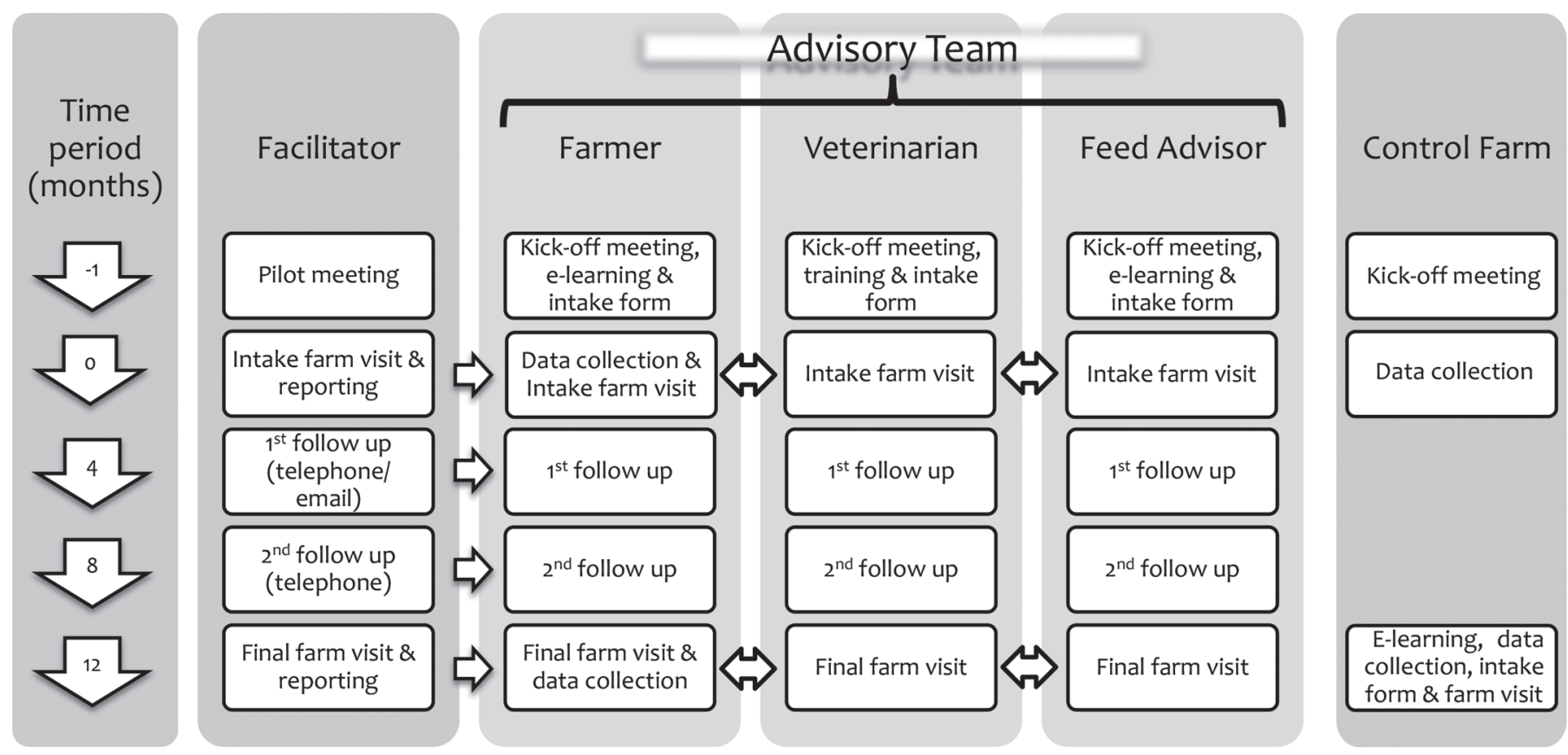

Figure 1. Study protocol describing the order of events in the study. During the initial and final farm visits, the farmer, veterinarian, and feed advisor met with a facilitator to develop and evaluate their animal health plan. 
between 1 (poor) and 5 (good) on 10 variables grouped into 2 scales: aspects concerning preparation for the consultation ( 5 variables) and quality of the collaboration of the advisory team in the animal health planning process (5 variables). The collaboration of the advisory team was again assessed by the facilitator after the final farm visit. The AMU data at farm level were derived from quarterly farm-level AMU reports (via MediRund) of the integral quality organization of the sector. Farmers in the intervention and control groups provided animal health and production data over the years preceding and during the study period. Most of these data were already available as part of the mandatory annual Farm Health Plan (Speksnijder et al., 2015c). Additional production and health parameters (e.g., official milk recordings, fertility reports, culling data) were derived from the herd improvement companies and dairy collaboration as far as these were available (Table 1). The objectives written in the activity plans were collected and grouped in the following categories: udder health, metabolic health and transition management, fertility, young stock rearing, housing and animal nursing, nutrition and production, collaboration within the advisory team, antimicrobial reduction, and miscellaneous.

\section{Statistical Analysis}

Individual farms were the unit for the analysis. Data were analyzed in SPSS version 22 (IBM SPSS Inc., Chicago, IL). Data on AMU and animal health parameters were checked for normal distribution by creating quantile-quantile (Q-Q) plots and performing the Kolmogorov-Smirnov test. $\log _{10}$ transformation or square root transformation was performed on nonnormally distributed data. The level of statistical significance was set at $\alpha=0.05$.

The level of compliance with the action points and accomplishment of the objectives were rated on a scale of 0 to $2(0=$ not at all performed or accomplished; $1=$ partly performed or accomplished; $2=$ fully performed or accomplished) to get an idea of the implementation and outcomes, respectively, of the animal health plans. The mean compliance score of the action points per single objective was calculated and ranged between 0 (none of the action points were performed) and 2 (all of the action points were fully performed). An overall "objective score" was given to each farm by calculating the mean from all single objective scores per farm as an indication of the level of accomplishment of the proposed objectives.

Table 1. Description of antibiotic use and animal health parameters on the study farms

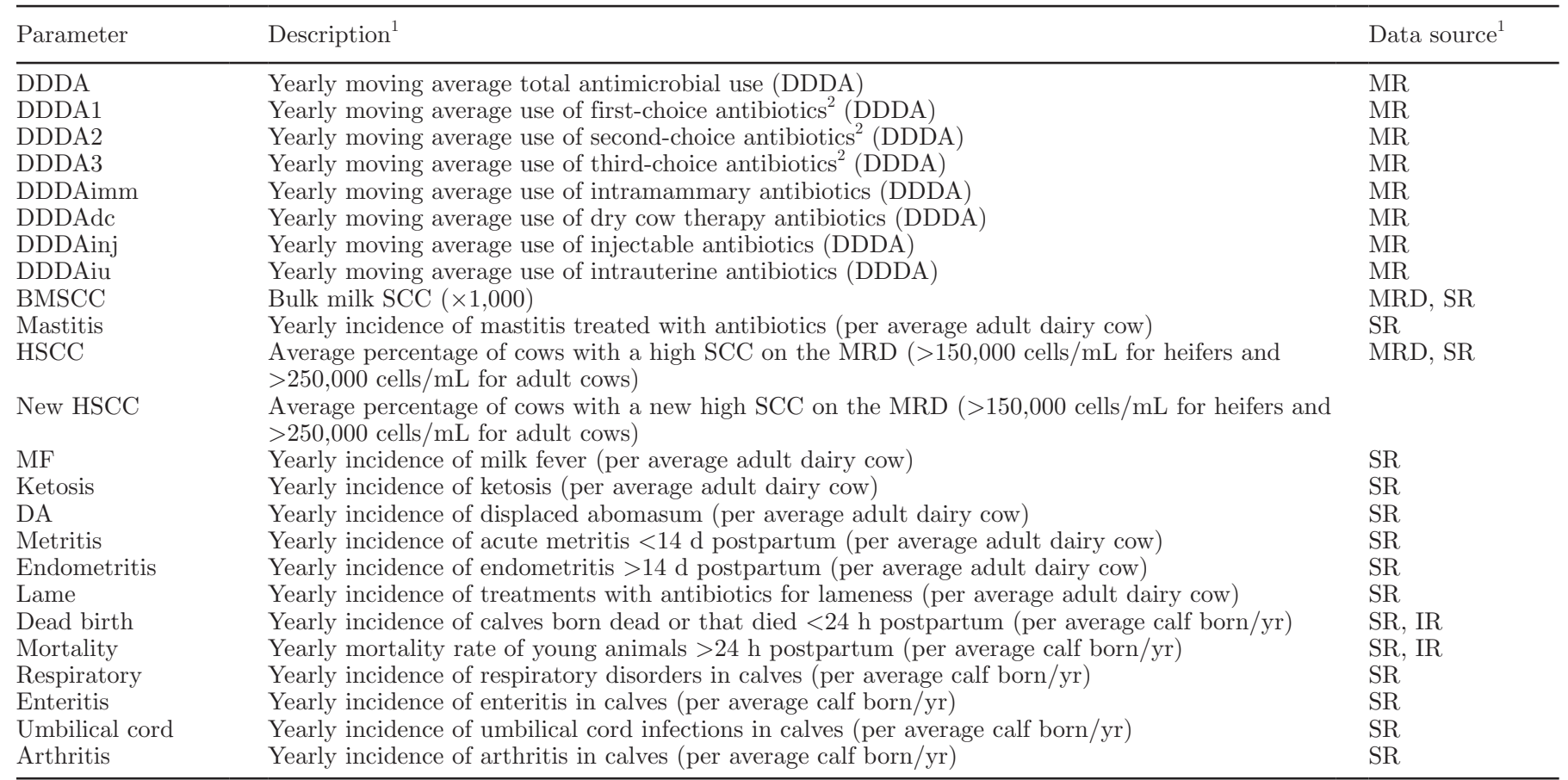

${ }^{1} \mathrm{DDDA}=$ defined daily dose animal; $\mathrm{MR}=$ MediRund, official antimicrobial use database for dairy farms; MRD = official milk recording data; $\mathrm{SR}=$ self-recorded by farmer; IR = official identification and registration system for food-producing animals in the Netherlands.

${ }^{2}$ First-, second-, and third-choice antibiotics as defined by the Dutch Veterinary Antimicrobial Policy Working Group. 
Linear mixed models for repeated measures with firstorder autoregressive covariance matrix were used, with variations in repeated measures (i.e., AMU and animal health parameters) as dependent variables. Assessment time (pre- and postintervention), group affiliation (intervention vs. control), and their interaction were used as factors (Ivemeyer et al., 2012; Tremetsberger and Winckler, 2015). Regression analyses were used to find relationships between several variables on intervention farms.

\section{RESULTS}

\section{Farm Characteristics}

All participating farmers had dairy farming as their primary occupation and kept their cows in freestall barns. Farmers were evenly distributed over the whole country. Participating intervention and control farms had an average milk quota of $912,111 \mathrm{~kg}( \pm 587,582)$ and $793,731 \mathrm{~kg}( \pm 277,436)$, respectively, at the start of the project. Total arable land was 60.1 ha $( \pm 31.2)$ and 51.2 ha $( \pm 15.4)$ per farm, respectively. Fifty percent of the intervention farms and $60 \%$ of the control farms grazed their cows on pastures during the summer period. Other characteristics are given in Table 2. Although intervention farms were on average larger in terms of numbers of animals, total annual milk production, and arable land, farm sizes were not significantly different between the 2 groups.

\section{AMU Characteristics}

The average AMU at the start of the study (at the second quarter of 2014) was numerically but not significantly higher in the intervention group (DDDA = $3.74 \pm 1.19$ ) compared with the control group (DDDA $=3.41 \pm 0.63 ; P=0.334$; independent samples $t$-test; Table 3). The AMU in the intervention and control groups decreased significantly during the study period $\left(P_{\text {period }}=0.001\right)$. In the intervention group we found a significantly lower AMU at the end of the study period compared with the start of the study $(-19 \%$; $P=0.026)$, whereas in the control group the AMU was not significantly different from the initial situation $(-14 \% ; P=0.091$; Table 3$)$. The rate of reduction in AMU between the intervention and control groups, however, was not significant $\left(P_{\text {group } \times \text { period }}=0.498\right)$. The average AMU in all dairy farms in the Netherlands in the same period decreased from 2.58 to 2.20 DDDA $(-15 \%)$. Retrospective data from 7,025 dairy farms with an AMU in the same percentile (between 3 and 6 DDDA) as the study farms in the first quarter of 2014 showed a $23 \%$ reduction in AMU (from 3.64 to

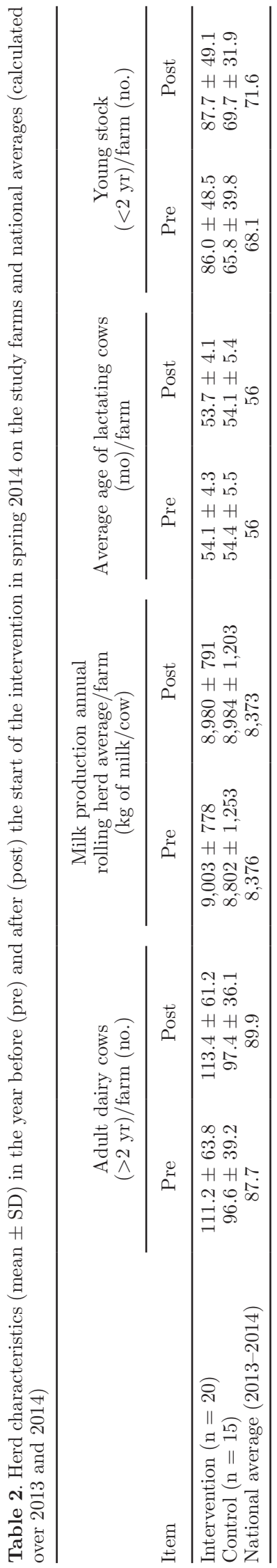

Journal of Dairy Science Vol. 100 No. 6, 2017 
Table 3. Antimicrobial use parameters (expressed in defined daily dosages animal) for intervention and control farms in the year before the start of the study (pre) and the year after the start of the study (post) and the effects of period (time), group (intervention or control), and period $\times$ group interaction on antimicrobial use

\begin{tabular}{|c|c|c|c|c|c|c|c|}
\hline Item & Period & Intervention & Control & $\begin{array}{c}\text { National } \\
\text { mean }\end{array}$ & \multicolumn{3}{|c|}{ Model effects ( $P$-value) } \\
\hline \multirow[t]{2}{*}{ Use of first-choice antibiotics } & Pre & $2.696 \pm 1.048$ & $2.067 \pm 0.887$ & 1.74 & 0.073 & 0.146 & 0.291 \\
\hline & Post & $2.283 \pm 0.579$ & $2.000 \pm 0.875$ & 1.59 & & & \\
\hline \multirow[t]{2}{*}{ Use of third-choice antibiotics } & Pre & $0.008 \pm 0.0167^{*}$ & $0.000 \pm 0.000^{*}$ & 0.00 & 0.401 & 0.872 & 0.064 \\
\hline & Post & $0.004 \pm 0.011$ & $0.005 \pm 0.016$ & 0.00 & & & \\
\hline \multirow[t]{2}{*}{ Antibiotics used for intramammary treatment } & Pre & $0.758 \pm 0.411$ & $0.739 \pm 0.352$ & 0.55 & 0.929 & 0.119 & 0.852 \\
\hline & Post & $0.649 \pm 0.288$ & $0.627 \pm 0.280$ & 0.52 & & & \\
\hline \multirow[t]{2}{*}{ Antibiotics used for dry cow therapy } & Pre & $1.531 \pm 0.630$ & $1.484 \pm 0.501$ & 1.20 & 0.758 & 0.009 & 0.816 \\
\hline & Post & $1.245 \pm 0.442$ & $1.213 \pm 0.592$ & 0.91 & & & \\
\hline Antibiotics used for injection & Pre & $1.281 \pm 0.667$ & $1.082 \pm 0.553$ & 0.68 & 0.545 & 0.014 & 0.339 \\
\hline
\end{tabular}

*Significant differences between pre- and postintervention periods or between intervention and control groups $(P<0.05)$.

2.89 DDDA) between the first and fourth quarters of 2014 (MediRund data, unpublished data), whereas the intervention and control farms had a reduction of $24 \%$ and $19 \%$, respectively, in the same period (which partly overlapped the study period).

Correcting for herd size or production level did not change the outcomes. The significant decrease in total DDDA between the year before and after the start of the study in the whole study group (intervention and control groups) was attributed mainly to a significant decrease in the use of second-class antimicrobials $\left(P_{\text {period }}\right.$ $=0.003)$, dry cow treatments $\left(P_{\text {period }}=0.009\right)$, and antimicrobials applied per injection $\left(P_{\text {period }}=0.014\right)$ during the pre- and postintervention periods.

\section{Health Parameters}

Animal health parameters were not significantly different between the intervention and control groups at the start of the study (independent samples $t$-test). Most animal health parameters improved slightly over time on intervention farms, which was more pronounced than on control farms. However, no significant differences between the intervention farms and the control farms were observed for changes in the major health parameters over the study period except for endometritis $\left(P_{\text {group } \times \text { period }}=0.006\right.$; Table 4$)$.

\section{Compliance and Its Effects on Intervention Farms}

A total of 92 objectives were formulated on the 20 intervention farms (mean $=4.6$; median $=4$ objec- tives/farm) along with 262 associated action points $($ mean $=13.1$ action points $/$ farm; median $=12.5)$. On the intervention farms (Table 5), 186 (71\%), 29 (11\%), and $47(18 \%)$ action points were fully, partly, and not implemented, respectively, and 34 (37\%), 38 (41\%), and $20(22 \%)$ objectives were fully, partly, and not accomplished, respectively.

The number of formulated objectives per farm was negatively associated with the mean compliance score for the action points and the percentage complete compliance of action points per farm in the intervention group $\left(P=0.029, \mathrm{R}^{2}=0.238, \beta=-0.112\right.$ and $P$ $=0.005, R^{2}=0.329, \beta=-0.092$, respectively; linear regression analysis) and tended to be negatively related to the rate of reduction in average yearly DDDA $(P$ $\left.=0.083, \mathrm{R}^{2}=0.158, \beta=-0.068\right)$. The percentage of complete compliance with the action points per farm was positively correlated with the rate of reduction in DDDA $\left(P=0.036, \mathrm{R}^{2}=0.222, \beta=0.529\right)$. However, we found no association between the overall objective score and changes in DDDA $(P=0.441)$ at the farm level.

An increase in the mean compliance score was associated with an increase in the accompanying objective score - odds ratio $=2.066$ (95\% CI: 1.076-3.967), Wald $\chi^{2}(1 \mathrm{df})=4.752, P=0.029$ (ordinal regression analysis) - and tended to be positively associated with the reduction rate in average yearly DDDA $\left(P=0.114, \mathrm{R}^{2}\right.$ $=0.133, \beta=0.271$; linear regression analysis).

The facilitator's rated quality of collaboration in the first consultancy meeting was positively associated with the rated quality of collaboration during the evalua- 
Table 4. Mean animal health parameters for intervention and control farms in the year before the start of the study (pre) and the year after the start of the study (post) and the effects of period (time), group (intervention or control), and period $\times$ group interaction on animal health parameters

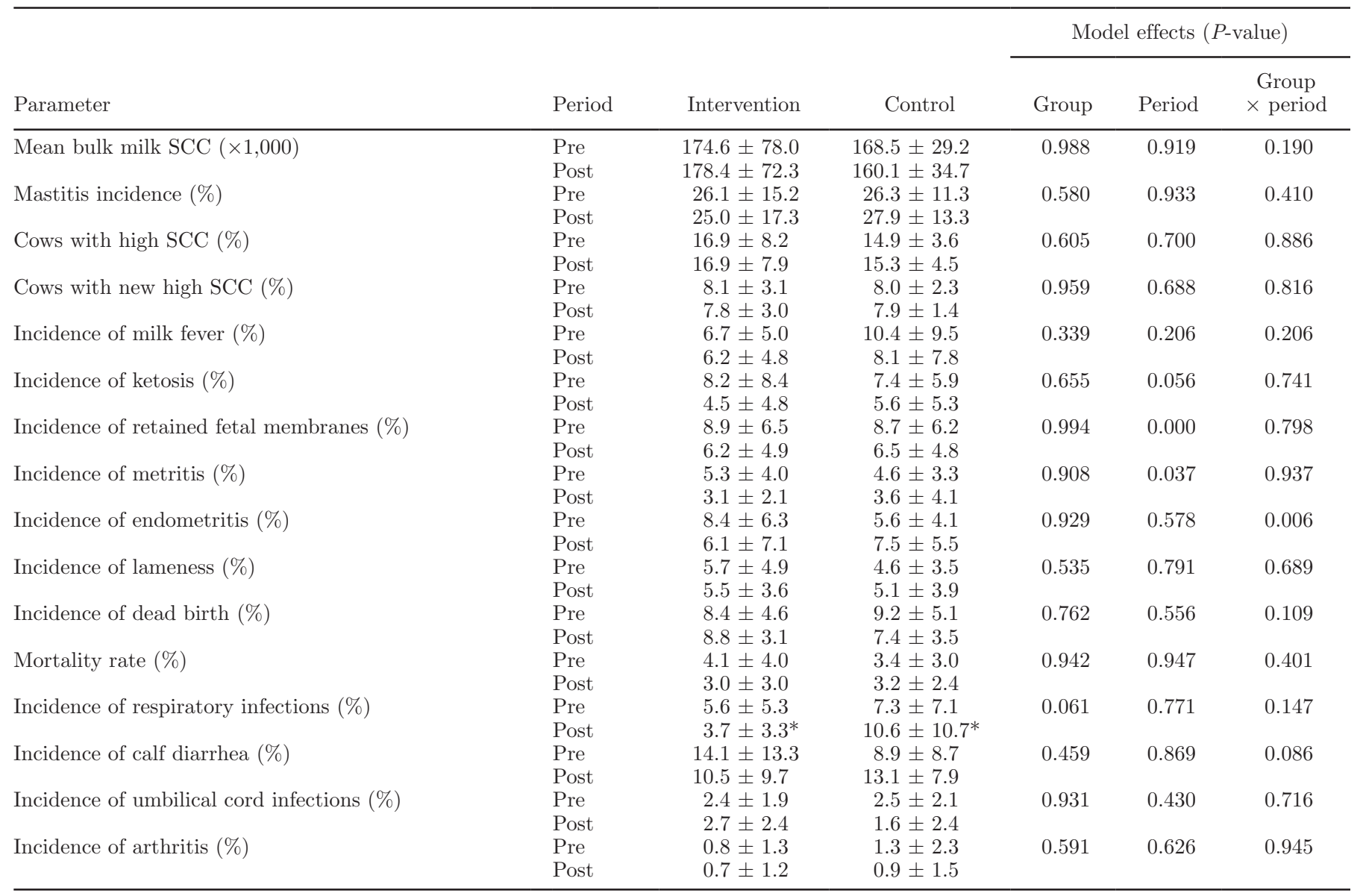

*Significant differences between pre- and postintervention periods $(P<0.05)$.

Table 5. Number of formulated objectives per focus area and percentage of intervention farms with objectives in this focus area, average objective score, ${ }^{1}$ total number of action points per focus area, mean compliance score for the action points per focus area, ${ }^{2}$ and percentage of action points with full compliance per focus area

\begin{tabular}{|c|c|c|c|c|c|}
\hline Focus area & $\begin{array}{c}\text { Formulated } \\
\text { objectives } \\
{[\text { no. (\% of farms)] }}\end{array}$ & $\begin{array}{c}\text { Mean } \\
\text { objective } \\
\text { score }(0-2)\end{array}$ & $\begin{array}{c}\text { Action } \\
\text { points/focus } \\
\text { area (no.) }\end{array}$ & $\begin{array}{l}\text { Mean } \\
\text { compliance } \\
\text { score }(0-2)\end{array}$ & $\begin{array}{l}\text { Action points } \\
\text { with full } \\
\text { compliance } \\
(\%)\end{array}$ \\
\hline Claw health & $13(60)$ & 1.08 & 29 & 1.24 & 55 \\
\hline Metabolic health and transition management & $9(35)$ & 1.33 & 23 & 1.43 & 61 \\
\hline Fertility & $11(50)$ & 1.00 & 35 & 1.50 & 71 \\
\hline Collaboration & $6(30)$ & 1.33 & 7 & 1.10 & 43 \\
\hline Nutrition and production & $7(35)$ & 1.29 & 19 & 1.80 & 84 \\
\hline Antibiotic reduction & $5(25)$ & 1.20 & 13 & 2.00 & 100 \\
\hline Miscellaneous & $5(25)$ & 0.80 & 13 & 1.22 & 54 \\
\hline Total or average & 92 & 1.16 & 262 & 1.50 & 72 \\
\hline
\end{tabular}

${ }^{1} 0=$ objective not accomplished; $1=$ objective partly accomplished; $2=$ objective fully accomplished.

${ }^{2} 0=$ noncompliant; 1 = partly compliant; 2 = fully compliant. 
tion consultancy meeting $\left(P=0.012, \mathrm{R}^{2}=0.300, \beta=\right.$ $0.734)$ and the mean objective score $\left(P=0.005, \mathrm{R}^{2}=\right.$ $0.358, \beta=0.351$; Figure 2 ). A positive tendency was apparent between the quality of collaboration in the first consultancy meeting and mean compliance score per farmer $\left(P=0.091, \mathrm{R}^{2}=0.151, \beta=0.206\right)$.

\section{DISCUSSION}

During the study period, total AMU over all study farms decreased significantly. Intervention farms had a significant reduction in total AMU between the start and end of the study, which was less pronounced and not significant on control farms. However, the rate of reduction was not significantly different between both groups. The results from our study indicate that structured animal health planning can reduce AMU while sustaining high animal health. This approach can be useful when a reduction in AMU is dictated by external forces. In the intervention group, positive relationships were found between the quality of collaboration among farmer, veterinarian, and feed adviser in the animal health planning process and the compliance with action plans and achievement of objectives; this suggests the added value of constructive collaboration between farmers and their advisers in animal health planning.

The facilitated animal health planning process in our study contained all the key features of a structured animal health planning strategy, including farm-specific targeted advice and the steps of a continuous improvement process, such as situation analysis, action planning, implementation, regular review, and adaptation (Clark et al., 2001; Tremetsberger and Winckler, 2015). Some possible limitations, however, were identified.

Animal health parameters were for a large part supplied by dairy farmers, and they might be based on farmers' memory rather than on proper record keeping, thus leading to errors. Where possible, these selfreported data were checked using other reliable data sources. However, we have no reason to assume that these errors will be different between groups and over time and therefore will not influence the differences found between intervention and control farms (Ivemeyer et al., 2012).

The MediRund quarterly AMU reports are based on the amount of prescribed antimicrobials at farm level and might deviate from the actual use in the study period due to stockpiling on a farm. However, taking

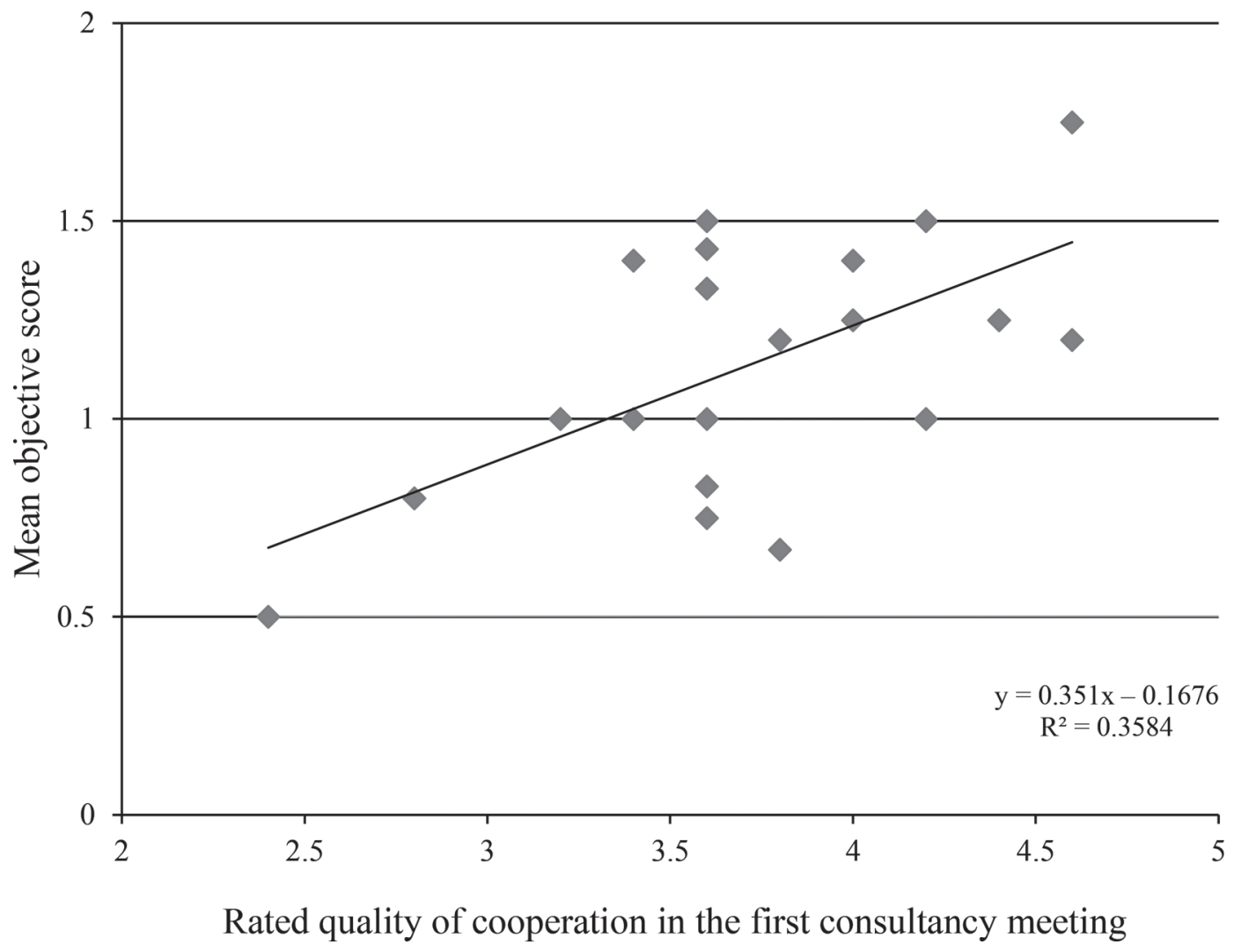

Figure 2. Relationship between rated quality of collaboration within the advisory team at the first consultancy meeting (5-point scale) and mean objective score (0-to- 2 scale). 
the yearly average AMU will negate the effect of stockpiling.

The absence of significant differences in AMU reduction rates and animal health parameters between the intervention and control farms during the study period might partly be explained by a lack of power. Despite many efforts to incorporate 50 farmers, only 39 farmers pledged to participate, and 4 control farms decided to withdraw during the study period. A period of 1 yr might be too short to find significant differences in animal health parameters and antimicrobial reduction rates (Bell et al., 2009; Ivemeyer et al., 2012; Tremetsberger and Winckler, 2015). Implementing management changes costs time, and it takes even more time until results become visible. We found a tendency for intervention farms to reduce faster than control farms over the period of $1 \mathrm{yr}$. In a recent study by Tisdall et al. (2015), it took some years before a real decline in AMU became observable.

In anticipation of the abolishment of the milk quota system in spring 2015, many dairy farmers increased their herd sizes. This may have resulted in farmers conservatively treating animals with antimicrobials to avoid any risk of losing an animal and being less inclined to cull animals with dormant diseases (Santman-Berends et al., 2016). This probably explains to some extent the relatively moderate reduction in AMU compared with the national reduction.

In our study, the focus was to improve multiple animal health parameters at the same time. From the literature, it appears that it is easier to focus all efforts on improving a single health parameter at a time (e.g., udder health; Tremetsberger and Winckler, 2015). This is substantiated by our findings that the number of objectives per action plan was inversely associated with the compliance with action points. It might therefore be advisable to focus on a limited number of objectives and action points when developing an animal health planning program.

\section{Determinants for AMU}

The reduction in AMU was attributed mainly to a decrease in antimicrobials used in dry cow therapy and second-choice antimicrobials. This can be explained by the introduction in early 2014 of a new guideline to set restrictions on the application of blanket dry cow therapy in order to shape the compulsory ban on prophylactic AMU and the routine use of second-choice antimicrobials in veterinary medicine in the Netherlands (Speksnijder et al., 2015c; Stichting Diergeneesmiddelen Autoriteit, 2015). This resulted in a $30 \%$ reduction in antimicrobial dry cow treatments in 2014 in the Netherlands (MediRund, unpublished data), of which a substantial part were second-choice antimicrobials (Stichting Diergeneesmiddelen Autoriteit, 2015).

In terms of animal health, available data indicated that herds in our study did not seem to perform differently from the average Dutch dairy herd when udder health and calf mortality were compared (SantmanBerends et al., 2014, 2016). The other animal health parameters were also comparable with the Dutch average. However, AMU remained higher than average on our study farms, indicating that determinants other than herd health level might also influence total AMU. In human medicine, the influence of attitudes, risk perception, and risk aversion of medical doctors is widely acknowledged to influence antimicrobial prescribing practices apart from rational clinical considerations (Hulscher et al., 2010). The same phenomenon likely is at play in dairy farming, where attitudes and risk perceptions of farmers and veterinarians probably influence the level of unnecessary (extended) antimicrobial treatments with subsequent effects on total AMU. Other authors have suggested that differences in mind-set and risk perception are determinants for total AMU in dairy farming; this needs further investigation (Swinkels et al., 2015; Stevens et al., 2016).

\section{Control Farms}

After the study on the intervention farms ended, it appeared that several control farms had started consultancy meetings with their veterinarian and feed adviser on their own initiative. Although limited to a minimum, some contact with control farms (by means of a newsletter) was regarded as essential to keeping them motivated to provide data. This unintentionally could have triggered them to initiate some measures together with their advisers. Simply being in the signaling zone for AMU did not require additional measures (Stichting Diergeneesmiddelen Autoriteit, 2015). The combination of being in a high benchmarking zone for AMU and being part of a study aiming to reduce AMU might have created a sense of urgency to work at reducing AMU and might have affected daily management. This phenomenon, known as the Hawthorn effect, is known to influence outcomes in randomized controlled studies in dairy farming as well as in studies aiming to alter the antimicrobial prescribing behavior of general practitioners (Mangione-Smith et al., 2002; Main et al., 2012; Tremetsberger and Winckler, 2015). This influence probably led to an underestimation of the real effects of our intervention. Recruiting farmers on a voluntary basis might have introduced a selection bias for farmers with more motivation to reduce AMU compared with fellow farmers. The approach as described in this study therefore may not necessarily work for dairy farmers 
with less motivation to reduce AMU (Tremetsberger and Winckler, 2015).

\section{Facilitated Animal Health Planning}

Feedback from participating advisory teams indicated that a facilitator contributed to a more structured approach of their animal health planning. In our study, the advisory teams could generate realistic objectives and implementable action points with positive effects on AMU reduction. The need for implementable action points that are supported by the farmer is substantiated by our findings that higher compliance led to better outcomes. A $71 \%$ complete compliance with the action plan is relatively high compared with other studies, probably indicating the importance of heavy involvement of the farmer and daily advisers in the planning process (Green et al., 2007; Barker et al., 2012; Whay et al., 2012; Tremetsberger and Winckler, 2015). Ownership of a farmer is known to be a key element in animal health planning as it improves compliance (Green et al., 2007; Vaarst et al., 2010; Kristensen and Jakobsen, 2011; Tremetsberger and Winckler, 2015). Bell et al. (2009), for example, found poor compliance and no effects of an action plan to improve lameness in dairy cows, probably because farmers and veterinarians were not fully involved in the assessment and planning processes (Tremetsberger and Winckler, 2015).

Another explanation for success could be that the facilitator frequently followed up on the action points, which improved compliance (Tremetsberger and Winckler, 2015). The downside of ownership and involvement of farmers could be that without specific assessment protocols, important health issues or risk factors potentially could be missed. Considering the high compliance with action points and high level of accomplishment of objectives, it might be possible that the advisers in our study hesitated to really challenge their farmer to formulate objectives that would have had a great effect on DDDA in order to maintain a good relationship (Speksnijder et al., 2015b). Independent external experts could possibly stimulate farmers to formulate more ambitious action points (Kristensen and Jakobsen, 2011). However, to safeguard compliance, these ambitious goals should not compromise ownership by the farmer.

\section{CONCLUSIONS}

In this article, we presented the results of an animal health planning intervention study with a control group on animal health parameters and AMU on conventional dairy farms in the Netherlands over the period of $1 \mathrm{yr}$.
A significant reduction in AMU was observed on study farms without obvious adverse effects on animal health parameters and productivity, indicating the value of structured animal health planning in reducing AMU while sustaining good animal health. Good collaboration among farmer, veterinarian, and feed adviser and ownership in animal health planning on dairy farms have a positive influence on the compliance with action plans and achievement of objectives.

\section{ACKNOWLEDGMENTS}

All participating farmers, veterinarians, and feed advisers are gratefully acknowledged. We also thank Friesland Campina (Amersfoort, the Netherlands) for helping us recruit dairy farmers, St. Anna Advies (Nijmegen, the Netherlands) for providing training for veterinarians on communication and advisory skills, Digiredo (Soest, the Netherlands) for their collaboration in the development of the e-learning course, and Wietske Dohmen (Faculty of Veterinary Medicine, Utrecht, the Netherlands), and Henry Voogd (ABRES rundveehouderij, Giessenburg, the Netherlands) for providing and analyzing national MediRund AMU data for farms in the signaling zone. This study was funded by ZonMW (Netherlands Organization for Health Research and Development, The Hague, the Netherlands), project no. 205100009.

\section{REFERENCES}

Agers $\varnothing$, Y., and F. M. Aarestrup. 2013. Voluntary ban on cephalosporin use in Danish pig production has effectively reduced extendedspectrum cephalosporinase-producing Escherichia coli in slaughter pigs. J. Antimicrob. Chemother. 68:569-572.

Barker, Z., J. Wright, R. Blowey, J. Amory, and L. E. Green. 2012. Uptake and effectiveness of interventions to reduce claw lesions in 40 dairy herds in the UK. Anim. Welf. 21:563-576.

Bell, N. J., M. J. Bell, T. G. Knowles, H. R. Whay, D. J. Main, and A. J. Webster. 2009. The development, implementation and testing of a lameness control programme based on HACCP principles and designed for heifers on dairy farms. Vet. J. 180:178-188.

Clark, R., J. Timms, A. MacCartney, K. Egerton-Warburton, N. O'Dempsey, and B. Radokovich. 2001. Achieving and enabling continuous improvement and innovation. Focussing action for impact on performance!-In a team? In a partnership? In a network? Accessed Mar. 7, 2017. www.regional.org.au/au/pdf/asa/2001/ clark.pdf.

Derks, M., L. M. A. van de Ven, T. van Werven, W. D. J. Kremer, and H. Hogeveen. 2012. The perception of veterinary herd health management by Dutch dairy farmers and its current status in the Netherlands: A survey. Prev. Vet. Med. 104:207-215.

Dorado-García, A., D. J. Mevius, J. J. H. Jacobs, I. M. van Geijlswijk, J. W. Mouton, J. A. Wagenaar, and D. J. J. Heederik. 2016. Quantitative assessment of antimicrobial resistance in livestock during the course of a nationwide antimicrobial use reduction in the Netherlands. J. Antimicrob. Chemother. 71:3607-3619.

Grave, K., V. F. Jensen, K. Odensvik, M. Wierup, and M. Bangen. 2006. Usage of veterinary therapeutic antimicrobials in Denmark, Norway and Sweden following termination of antimicrobial growth promoter use. Prev. Vet. Med. 75:123-132. 
Green, M. J., K. A. Leach, J. E. Breen, L. E. Green, and A. J. Bradley. 2007. National intervention study of mastitis control in dairy herds in England and Wales. Vet. Rec. 160:287-293.

Hulscher, M. E., J. van der Meer, and R. Grol. 2010. Antibiotic use: How to improve it? Int. J. Med. Microbiol. 300:351-356.

Ivemeyer, S., G. Smolders, J. Brinkmann, E. Gratzer, B. Hansen, B. I. Henriksen, J. Huber, C. Leeb, S. March, and C. Mejdell. 2012. Impact of animal health and welfare planning on medicine use, herd health and production in European organic dairy farms. Livest. Sci. 145:63-72.

Jansen, J., C. D. M. Steuten, R. J. Renes, N. Aarts, and T. J. G. M. Lam. 2010. Debunking the myth of the hard-to-reach farmer: Effective communication on udder health. J. Dairy Sci. 93:1296-1306.

Kristensen, E., and E. B. Jakobsen. 2011. Challenging the myth of the irrational dairy farmer; understanding decision-making related to herd health. N. Z. Vet. J. 59:1-7.

LeBlanc, S. J., K. D. Lissemore, D. F. Kelton, T. F. Duffield, and K. E. Leslie. 2006. Major advances in disease prevention in dairy cattle. J. Dairy Sci. 89:1267-1279.

Main, D. C. J., K. A. Leach, Z. E. Barker, A. K. Sedgwick, C. M. Maggs, N. J. Bell, and H. R. Whay. 2012. Evaluating an intervention to reduce lameness in dairy cattle. J. Dairy Sci. 95:2946-2954.

Mangione-Smith, R., M. N. Elliott, L. McDonald, and E. A. McGlynn. 2002. An observational study of antibiotic prescribing behavior and the Hawthorne effect. Health Serv. Res. 37:1603-1623.

MARAN. 2015. Monitoring of antimicrobial resistance and antibiotic usage in animals in the Netherlands in 2015.

Postma, M., K. D. Stärk, M. Sjölund, A. Backhans, E. G. Beilage, S. Lösken, C. Belloc, L. Collineau, D. Iten, and V. Visschers. 2015. Alternatives to the use of antimicrobial agents in pig production: A multi-country expert-ranking of perceived effectiveness, feasibility and return on investment. Prev. Vet. Med. 118:457-466.

Santman-Berends, I. M., M. Buddiger, A. Smolenaars, C. Steuten, C. Roos, A. Van Erp, and G. Van Schaik. 2014. A multidisciplinary approach to determine factors associated with calf rearing practices and calf mortality in dairy herds. Prev. Vet. Med. 117:375-387.

Santman-Berends, I. M., J. Swinkels, T. Lam, J. Keurentjes, and G. van Schaik. 2016. Evaluation of udder health parameters and risk factors for clinical mastitis in Dutch dairy herds in the context of a restricted antimicrobial usage policy. J. Dairy Sci. 99:2930-2939.

Speksnijder, D. C., A. Jaarsma, A. Gugten, T. Verheij, and J. Wagenaar. 2015a. Determinants associated with veterinary antimicrobial prescribing in farm animals in the Netherlands: A qualitative study. Zoonoses Public Health 62(Suppl. 1):39-51.

Speksnijder, D. C., A. Jaarsma, T. Verheij, and J. Wagenaar. 2015b. Attitudes and perceptions of Dutch veterinarians on their role in the reduction of antimicrobial use in farm animals. Prev. Vet. Med. 121:365-373.

Speksnijder, D. C., D. Mevius, C. Bruschke, and J. Wagenaar. 2015c. Reduction of veterinary antimicrobial use in the Netherlands. The Dutch success model. Zoonoses Public Health 62(Suppl. 1):79-87.

Stevens, M., S. Piepers, and S. De Vliegher. 2016. Mastitis prevention and control practices and mastitis treatment strategies associated with the consumption of (critically important) antimicrobials on dairy herds in Flanders, Belgium. J. Dairy Sci. 99:2896-2903.

Stichting Diergeneesmiddelen Autoriteit. 2014. Usage of antibiotics in agricultural livestock in the Netherlands in 2013. Trends and benchmarking of livestock farms and veterinarians. Accessed Mar. $22, \quad 2017 . \quad$ www.autoriteitdiergeneesmiddelen.nl/Userfiles/pdf/ SDa-rapporten/sda-report-usage-of-antibiotics-in-agricultureallivestock-in-the-netherlands-in-2013--september-2014.pdf.

Stichting Diergeneesmiddelen Autoriteit. 2015. Usage of antibiotics in agricultural livestock in the Netherlands in 2014. Trends and benchmarking of livestock farms and veterinarians. Accessed Mar. 22, 2017. http://www.autoriteitdiergeneesmiddelen.nl/Userfiles/ pdf/SDa-rapporten/def-sda-rapport-ab-2014-engels-v2-aangepast102015-incl-erratum.pdf.

Swinkels, J. M., A. Hilkens, V. Zoche-Golob, V. Krömker, M. Buddiger, J. Jansen, and T. Lam. 2015. Social influences on the duration of antibiotic treatment of clinical mastitis in dairy cows. J. Dairy Sci. 98:2369-2380.

Tisdall, D. A., K. K. Reyher, and D. C. Barrett. 2015. Making farm animal practice work without critically important antimicrobials. Cattle Pract. 23:306-309.

Tremetsberger, L., C. Leeb, and C. Winckler. 2015. Animal health and welfare planning improves udder health and cleanliness but not leg health in Austrian dairy herds. J. Dairy Sci. 98:6801-6811.

Tremetsberger, L., and C. Winckler. 2015. Effectiveness of animal health and welfare planning in dairy herds: A review. Anim. Welf. 24:55-67.

Vaarst, M., T. W. Bennedsgaard, I. Klaas, T. B. Nissen, S. M. Thamsborg, and S. Østergaard. 2006. Development and daily management of an explicit strategy of nonuse of antimicrobial drugs in twelve Danish organic dairy herds. J. Dairy Sci. 89:1842-1853.

Vaarst, M., E. Gratzer, M. Walkenhorst, S. Ivemeyer, J. Brinkmann, S. March, L. K. Whistance, G. Smolders, E. Stöger, and J. Huber. 2010. Farmer groups for animal health and welfare planning in European organic dairy herds. Pages 683-691 in Proceedings of the 9th European IFSA Conference, Vienna. July 4-7, 2010 http://orgprints.org/17867/1/vaarst-etal-2010-European-IFSASymposium.pdf.

Van Boeckel, T. P., C. Brower, M. Gilbert, B. T. Grenfell, S. A. Levin, T. P. Robinson, A. Teillant, and R. Laxminarayan. 2015. Global trends in antimicrobial use in food animals. Proc. Natl. Acad. Sci. USA 112:5649-5654.

Whay, H. R., Z. E. Barker, K. A. Leach, and D. C. J. Main. 2012 Promoting farmer engagement and activity in the control of dairy cattle lameness. Vet. J. 193:617-621.

WHO (World Health Organization). 2012. The evolving threat of antimicrobial resistance: Options for action. WHO, Geneva, Switzerland.

WHO (World Health Organization). 2015. Antimicrobial resistance: Draft global action plan on antimicrobial resistance. WHO, Geneva, Switzerland. 